\title{
Crotylation and Homopropargylation by Flow Technology
}

Key words

microreactor

flow chemistry

asymmetric

synthesis

chain elongation
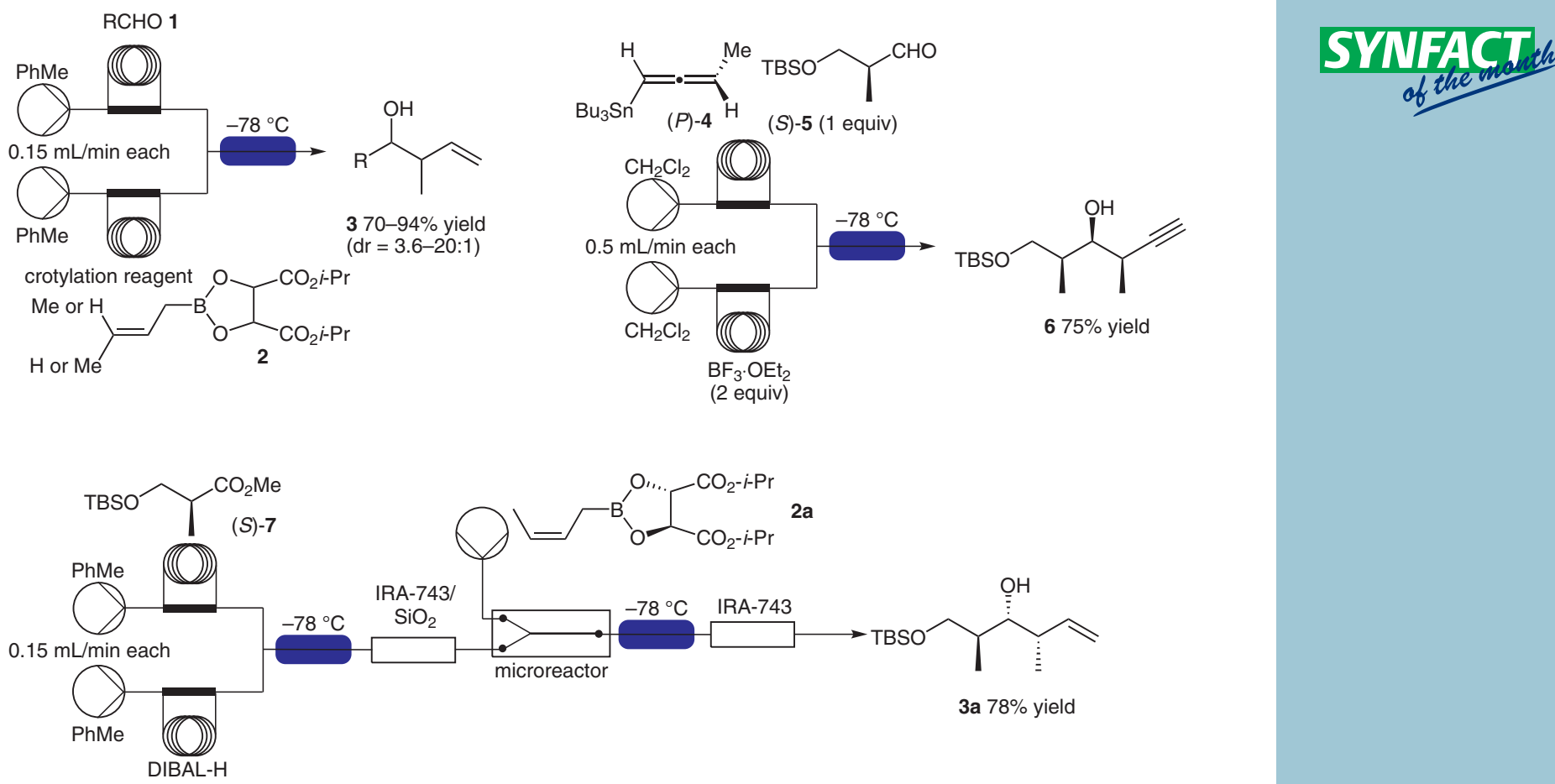

Significance: A new flow reaction technology for diastereoselective Roush crotylation and Marshall homopropargylation as well as in-line purification protocols was described. Thus, the flow Roush reaction of aldehydes $\mathbf{1}$ with boronate $\mathbf{2}$ gave the corresponding homoallyl alcohols 3 in 70-94\% yield with syn selectivity (syn/anti $=3.6-20: 1)$. Similarly, the diastereoselective flow Marshall homopropargylation of allene $(P)-\mathbf{4}$ with aldehyde (S)-5 was carried out with $\mathrm{BF}_{3} \cdot \mathrm{OEt}_{2}$ to give homopropargyl alcohol 6 in $75 \%$ yield.
Comment: An automated multi-step flow protocol [(1) the reduction of ester (S)-7 with DIBAL; (2) the purification with IRA-743/SiO 2 ; (3) the treatment with boronate $\mathbf{2 a}$ in a microreactor; (4) the purification with IRA-743] afforded $\mathbf{3 a}$ in $78 \%$ yield. The authors indicated that flushing the pumps, valves, and reaction coils with isopropyl alcohol, followed by acetone and then the dry solvent of choice under an inert atmosphere for at least two hours was needed for a suitable process (to eliminate all traces of water from the reactor). 